\title{
Effects of 3\% trehalose as an adjuvant treatment after LASIK
}

\author{
This article was published in the following Dove Press journal: \\ Clinical Ophthalmology \\ 16 February 2017 \\ Number of times this article has been viewed
}

Purpose: To evaluate the effect of $3 \%$ trehalose as an adjuvant in the standard treatment after laser-assisted in situ keratomileusis.

Design: Interventional prospective comparative single-blind study.

Setting: Department of Ophthalmology, Hospital Quirón Zaragoza, Spain.

Methods: A total of 26 eyes (13 patients) were included, of which 12 eyes (group 1) received conventional treatment with lubricant drops of hyaluronic acid (0.15\%) and 14 eyes (group 2) received, additionally, an ophthalmic solution of $3 \%$ trehalose. Pre- and postoperative qualityof-life tests and vital stains, tear breakup time, and osmolarity measurements were made.

Results: We obtained statistically significant differences between the groups in the Symptom Assessment in Dry Eye test in all visits with respect to severity, and in the postoperative day 1 visit with respect to frequency, in all cases favoring the trehalose treatment. The values of osmolarity were not significantly different between groups. However, we did find significant differences in the Oxford scale in day 90 for the trehalose treatment $(P<0.001)$, and in the National Eye Institute scale in day $30(P=0.02)$.

Conclusion: The results of this exploratory study indicate that the adjuvant treatment with $3 \%$ trehalose could be superior with respect to the standard treatment, with improvements in the objective and subjective parameters of tear quality.

Keywords: dry eye syndrome, trehalose, hyaluronic acid, LASIK, osmolarity

\section{Introduction}

Laser-assisted in situ keratomileusis (LASIK) is currently the most common refractive surgery treatment performed in the USA, with $>600,000$ working-age patients treated yearly. ${ }^{1}$ The quick visual rehabilitation after the procedure and highly predictable outcomes make this technique one of the most widely distributed worldwide. However, postsurgical adverse effects such as dry eye can occur with a prevalence that has been estimated between $0.8 \%$ and $40 \% .^{1-4}$ The damage to the afferent sensory innervation caused by the cutting of the corneal flap and the stromal ablation determines a loss of corneal sensitivity with reduced tear production, decreased blinking rate, altered tear film, and loss of goblet cells. ${ }^{5,6}$ Although most patients suffer from dry eye symptoms only temporally, some patients can develop a chronic condition, which significantly undermines their satisfaction with the surgery.

Dry eye disease is a multifactorial syndrome that causes discomfort, visual disturbances, and tear film instability, which can potentially damage the ocular surface. It is accompanied by increased osmolarity of the tear film and inflammation of the ocular surface. ${ }^{7}$ Treatment is based on topical application of tear-substitute compounds containing various polymers and viscosity agents that provide lubrication to the tear surface. However, there is no perfect formula for the optimal replacement of the tear
Correspondence:Antonio J Mateo Orobia Hospital Quirón, Avda. Gómez Laguna 82, Zaragoza 50012, Spain Email catarata@comz.org 
film, and most commercial formulations just mimic the composition of human tears. ${ }^{8}$

Trehalose, considered an osmoprotectant, is a disaccharide derived from glucose. It is found naturally in many organisms and it has been recognized as key to anhydrobiosis, that is, the ability of an organism to survive long periods of desiccation. ${ }^{9}$ Its osmoprotectant function in eukaryotic cells includes the stabilization of the lipid bilayers and labile proteins to desiccation, and protection against oxidative stress. ${ }^{10}$

The development of new therapies to recover tear homeostasis in the shortest time possible after surgery is of special interest to the ophthalmologist. The objective of our study was to determine the effects of treatment with trehalose as an adjuvant osmoprotectant agent after standard LASIK, using objective and subjective parameters of ocular dryness.

\section{Patients and methods}

This interventional, prospective, comparative, single-blind study included 26 eyes of 13 patients who underwent bilateral LASIK between December 2013 and June 2014 in the Department of Ophthalmology at the Hospital Quirón (Zaragoza, Spain). The gender distribution of patients was $92.3 \%$ males and $7.7 \%$ females. The age of the patients ranged between 29 and 43 years (mean \pm standard deviation [SD]: 35.23 \pm 5.23$)$.

This study adhered to the principles of the Declaration of Helsinki and was approved by the Ethics Committee of Aragon (CEICA), Institute of Health Research (IIS, Aragón, Spain). All patients were informed orally and in writing of the surgical procedure, potential risks and complications, and implications of accepting this study.

The study included 26 eyes of 13 patients whose consent was obtained verbally and in writing. Patients who met the inclusion criteria of the study were candidates for LASIK surgery aged between 18 and 45 years. Exclusion criteria rejected patients with systemic treatments or processes that could alter the results in the study, such as acne rosacea or taking oral contraception; and ophthalmological criteria such as refraction defects higher than 3 sphero-cylindrical diopters; wearing contact lenses before the screening visit (7 days in the case of soft contact lenses, 21 days in case of hard contact lenses); treatments for eye diseases, such as uveitis, corneal herpes, trauma, or corneal infection during the 90 days prior to the intervention; changes in eyelid anatomy or blepharitis; patients with corrected visual acuity (VA) $<20 / 20$ Snellen; or patients with confirmed diagnosis of dry eye in the preoperative visit. Dry eye was defined by the presence of one or more of the following criteria: decreased basal tear secretion (Schirmer with anesthesia $<10 \mathrm{~mm} / 5$ minutes); a tear breakup time (TBUT) value $<8$ seconds; reduced blinking rate ( $<7$ per minute) or a score $>1$ in the Oxford scale in the vital stain tests (fluorescein and lissamine green). The appearance of any complication during surgery was also an exclusion criterion. Both preoperative and postoperative examination at 1, 7, 30, and 90 days included symptom assessment scales such as the overall score of the Ocular Surface Disease Index (OSDI, ${ }^{11}$ symptoms and quality of life in everyday tasks, scored from 0 to 100) and the Symptom Assessment in Dry Eye (SANDE, ${ }^{12}$ scale of frequency of symptoms, quantified by an analogic visual scale) questionnaires. Tear osmolarity was measured from $50 \mathrm{~nL}$ of the temporal inferior lagrimal meniscus, as determined by Tearlab ${ }^{\circledR}$ (OcuSense, Inc., San Diego, CA, USA). We measured objective indices of ocular dryness with lissamine green staining (Lissaver Plus strips, Contopharma, Interlaken, Switzerland) quantitated by the van Bijsterveld ${ }^{13}$ and Oxford ${ }^{14}$ scales, fluorescein staining (fluorescein 2\%, Alcon Cusí, El Masnou, Spain) quantitated by the National Eye Institute (NEI) ${ }^{15}$ scale, and TBUT, respecting this scale sequence. Staining with both dyes was applied with stripes on the upper bulbar conjunctiva.

With respect to functional variables, we quantified monocular best corrected distance visual acuity $(6 \mathrm{~m})$ in the preoperative visit and spontaneous monocular VA in each of the postoperative visits by the ETDRS ${ }^{\circledR}$ system. Scanning conditions for all distances were identical and patients were instructed to apply the last drop of treatment 2 hours before scanning in a quiet and illuminated room in photopic conditions $\left(70 \mathrm{~cd} / \mathrm{m}^{2}\right)$.

All patients underwent sequential binocular surgery. The procedure involved creating a flap $120 \mu \mathrm{m}$ in thickness, $9.5 \mathrm{~mm}$ in diameter, and a $50^{\circ}$ top hinge with a macerator Zyoptix XP microkeratome (Bausch \& Lomb, Berlin, Germany) after administration of topical anesthetic oxybuprocaine, and placement of an eye speculum and sterile cloth. Ablation to achieve emmetropia was conducted with the excimer laser system Visx Star S4 ${ }^{\circledR}$ (Abbott Laboratories, Inc., Abbott Park, IL, USA) with a treatment diameter of $6.5 \mathrm{~mm}$. Later the interface was abundantly irrigated with balanced saline solution and repositioning of the flap in the surgical bed. Postoperative treatment with dexamethasone $(1 \mathrm{mg} / \mathrm{mL})$ and topical tobramycin $\left(3 \mathrm{mg} / \mathrm{mL}\right.$; Tobradex ${ }^{\circledR}$, Alcon-Cusi, El Masnou, Spain) every 2 hours was gradually reduced during 10 days. Patients were assigned randomly to two treatment groups of different lubricants. In group 1 , lubricating drops with hyaluronic acid (HA; $0.15 \%$ 
Hyabak $^{\circledR}$, Thea, Clermont-Ferrand, France) were given every 2 hours during the first 10 days and 6 times a day from day 11 until 3 months postsurgery. In group 2, the same dosage of Hyabak plus an aqueous ophthalmic solution of $3 \%$ trehalose (Thealoz ${ }^{\circledR}$, Thea, Clermont-Ferrand, France) was prescribed 4 times a day, always administered 5 minutes before the HA-rich solution and starting the application 3 days before surgery.

\section{Statistical analysis}

Data analysis was performed with the Statistical Package for Social Sciences (SPSS, version 19.0, Chicago, IL, USA). We performed descriptive statistics of all variables collected, with frequency tables for nominal variables, and measures of central tendency and dispersion for continuous variables (confidence intervals of $95 \%$ ).

We started by performing a baseline homogeneity analysis of the treatment groups. We used the Fisher's exact test for comparison of categorical variables, the MannWhitney $U$-test for comparison of ordinal variables, and the Student's $t$-test for continuous variables.

Even though we did not detect statistically significant differences between groups at baseline, in order to reduce intrasubject variability and increase statistical power, we chose to contrast paired data corrected to the presurgery values. To compare continuous variables we used analysis of covariance comparing treatment groups by taking into account baseline measurements. In the case of ordinal variables we used the Wilcoxon sign test. For all tests we established the level of significance at $P<0.05$.

\section{Results}

Twelve eyes were assigned to the treatment group 1 and 14 eyes assigned to group 2, and all completed the study.
Group 1 was composed entirely of men with a mean age of $36.17 \pm 4.36$ years. No statistically significant differences were found with respect to group 2, where the proportion of men was $85.71 \%(P>0.05$, Fisher $)$ and a mean age of $34.43 \pm 6.11$ years $(P>0.05, t$-test $)$. The average corrected refractive defect was 3.5 myopic diopters (D) in terms of spherical equivalent, with a range from 2.5 to $4 \mathrm{D}$. We also obtained no differences between the groups ( $P=0.134$, Mann-Whitney $U$-test).

Table 1 shows the preoperative values for all variables for both study groups. No statistically significant baseline differences can be observed for any of them.

Regarding the test of subjective assessment of symptoms of dry eye, no statistically significant differences were observed between the groups with the OSDI test. The SANDE test showed significant differences in the frequency on day 1 , and on all visits with respect to severity of symptoms for treatment with trehalose (Table 2).

No statistically significant differences were detected regarding tear osmolarity between the groups throughout the postoperative visits. We noted that the highest values of osmolarity were registered 24 hours after surgery. The lowest values were observed on the second visit in both groups (Table 2; Figure 1).

Table 2 shows the mean, $\mathrm{SD}$, and statistical significance of values of lissamine green (van Bijsterveld and Oxford scales) and fluorescein (NEI scale) staining, in addition to the TBUT values and osmolarity. We could observe significant differences on day 90 of the Oxford scale in favor of treatment with trehalose ( $P=0.00$, Mann-Whitney $U$-test) and on day 30 of the NEI scale ( $P=0.02$, Mann-Whitney $U$-test) also for the same treatment group.

Table 3 presents the values of tear osmolarity and staining with lissamine green (Oxford scale) for each eye explored in the preoperative and all postoperative visits.

Table I Preoperative values (mean \pm standard deviation) and range of variables with respect to dry eye

\begin{tabular}{|c|c|c|c|}
\hline Diagnostic tests & Group I & Group 2 & $P$-value \\
\hline Ocular Surface Disease Index & $6.94 \pm 9.29(0-25), N=6$ & $7.08 \pm 12.24(0-33.3), \mathrm{N}=7$ & $0.98 *$ \\
\hline SANDE (symptom frequency) & $1.92 \pm 2.11(0-6), N=6$ & $0.7 \mathrm{I} \pm 0.76(0-2), \mathrm{N}=7$ & $0.184^{*}$ \\
\hline SANDE (severity) & $1.25 \pm 1.47(0-4), \mathrm{N}=6$ & $0.29 \pm 0.49(0-1), N=7$ & $0.13^{*}$ \\
\hline Osmolarity & $302.4 \pm 13.59(277-325), \mathrm{N}=12$ & $310.14 \pm 14.78(288-342), N=14$ & $0.18^{*}$ \\
\hline Lissamine green staining (van Bijsterveld) & $1.25 \pm 1.06(0-3), \mathrm{N}=12$ & $0.69 \pm 0.75(0-2), N=14$ & $0.18^{* *}$ \\
\hline Lissamine green staining (Oxford) & $0.5 \pm 0.52(0-1), \mathrm{N}=12$ & $0.43 \pm 0.5 \mathrm{I}(0-1), \mathrm{N}=14$ & $0.74 * *$ \\
\hline Fluorescein staining (National Eye & $0.08 \pm 0.29(0-1), N=12$ & $0.07 \pm 0.27(0-1), N=14$ & $0.96 * *$ \\
\hline \multicolumn{4}{|l|}{ Institute/Industry Workshop) } \\
\hline Tear breakup time & $|3.83 \pm 6.0|(7-25), N=12$ & II.II $\pm 6.63(5.5-26), \mathrm{N}=14$ & $0.29 *$ \\
\hline Schirmer with anesthesia & $16 \pm 5.16(10-25), \mathrm{N}=12$ & $15.36 \pm 1.34(\mid 5-20), N=14$ & $0.66 *$ \\
\hline
\end{tabular}

Notes: *Student's $t$-test; **Mann-Whitney U-test; $P<0.05$. Data shown as mean \pm standard deviation (range). Abbreviation: SANDE, Symptom Assessment in Dry Eye. 
Table 2 Postoperative values (mean \pm SD) and statistical significance between the groups

\begin{tabular}{|c|c|c|c|c|c|c|c|c|c|}
\hline \multirow{2}{*}{$\begin{array}{l}\text { Diagnostic } \\
\text { tests }\end{array}$} & \multirow[t]{2}{*}{$\mathbf{N}$} & \multicolumn{2}{|l|}{ Day I } & \multicolumn{2}{|l|}{ Day 7} & \multicolumn{2}{|l|}{ Day 30} & \multicolumn{2}{|l|}{ Day 90} \\
\hline & & Mean \pm SD & Significance & Mean \pm SD & Significance & Mean \pm SD & Significance & Mean \pm SD & Significance \\
\hline \multicolumn{10}{|l|}{ OSDI } \\
\hline $\mathrm{HA}+$ trehalose & 7 & $11.21 \pm 18.8$ & $0.1 I^{*}$ & $7.14 \pm 3.9$ & $0.03^{*}$ & $3.27 \pm 2.6$ & $0.035^{*}$ & $2.68 \pm 2.88$ & $0.16 *$ \\
\hline $\mathrm{HA}$ & 6 & $31.72 \pm 24.1$ & & $16.76 \pm 9.2$ & & II. $46 \pm 8.6$ & & $5.9 \pm 4.83$ & \\
\hline \multicolumn{10}{|c|}{ OSDI (difference with baseline) } \\
\hline $\mathrm{HA}+$ trehalose & 7 & $4.13 \pm 26.1$ & $0.09 * *$ & $0.06 \pm 13.8$ & $0.22 * *$ & $-3.8 I \pm 13.6$ & $0.32 * *$ & $-4.4 \pm 13.5$ & $0.66 * *$ \\
\hline $\mathrm{HA}$ & 6 & $24.77 \pm 29.7$ & & $9.82 \pm 11.1$ & & $4.5 I \pm 7.7$ & & $-1.04 \pm 6.3$ & \\
\hline \multicolumn{10}{|l|}{ SANDE frequency } \\
\hline $\mathrm{HA}+$ trehalose & 7 & $1.14 \pm 1.1$ & $0.03 *$ & $1.71 \pm 1.2$ & $0.3^{*}$ & $1.50 \pm 1.7$ & $0.3 I^{*}$ & $0.29 \pm 0.4$ & $0.03 *$ \\
\hline $\mathrm{HA}$ & 6 & $4.0 \pm 2.8$ & & $2.92 \pm 2.6$ & & $2.67 \pm 2.2$ & & $1.33 \pm 1.1$ & \\
\hline \multicolumn{10}{|c|}{ SANDE frequency (difference with baseline) } \\
\hline $\mathrm{HA}+$ trehalose & 7 & $0.43 \pm 1.1$ & $0.01 * *$ & $1.0 \pm 1.6$ & $0.09 * *$ & $0.79 \pm 1.9$ & $0.12^{* *}$ & $-0.43 \pm 0.6$ & $0.06 * *$ \\
\hline $\mathrm{HA}$ & 6 & $2.08 \pm 3.9$ & & $1.0 \pm 3.5$ & & $0.75 \pm 3$ & & $-0.58 \pm 2.0$ & \\
\hline \multicolumn{10}{|l|}{ SANDE severity } \\
\hline $\mathrm{HA}+$ trehalose & 7 & $0.57 \pm 0.8$ & $0.01 *$ & $0.79 \pm 0.7$ & $0.0 I^{*}$ & $0.50 \pm 0.5$ & $0.02 *$ & $0.36 \pm 0.5$ & $0.01 *$ \\
\hline $\mathrm{HA}$ & 6 & $3.50 \pm 2.1$ & & $2.08 \pm 0.9$ & & $1.92 \pm 1.3$ & & $1.17 \pm 0.5$ & \\
\hline \multicolumn{10}{|c|}{ SANDE severity (difference with baseline) } \\
\hline $\mathrm{HA}+$ trehalose & 7 & $0.29 \pm 0.8$ & $0.00 * *$ & $0.50 \pm 0.8$ & $0.0 I^{* *}$ & $0.21 \pm 0.7$ & $0.01 * *$ & $0.07 \pm 0.4$ & $0.02 * *$ \\
\hline $\mathrm{HA}$ & 6 & $2.25 \pm 2.9$ & & $0.83 \pm 1.9$ & & $0.67 \pm 1.9$ & & $-0.08 \pm 1.6$ & \\
\hline \multicolumn{10}{|l|}{ Osmolarity } \\
\hline $\mathrm{HA}+$ trehalose & 14 & $311.6 \pm 17.6$ & $0.54 *$ & $306.07 \pm 11.3$ & $0.48^{*}$ & $308.86 \pm 16.7$ & $0.73^{*}$ & $306.21 \pm 9.6$ & $0.65^{*}$ \\
\hline $\mathrm{HA}$ & 12 & $308.17 \pm 9.3$ & & $302.90 \pm 9.9$ & & $306.92 \pm 10.3$ & & $304.58 \pm 8.2$ & \\
\hline \multicolumn{10}{|c|}{ Osmolarity (difference with baseline) } \\
\hline $\mathrm{HA}+$ trehalose & 14 & $1.50 \pm 14.6$ & $0.25 * *$ & $-4.07 \pm 16.8$ & $0.11 * *$ & $-1.29 \pm 16.6$ & $0.3 * *$ & $-3.93 \pm 11.8$ & $0.26 * *$ \\
\hline $\mathrm{HA}$ & 12 & $5.75 \pm 16.2$ & & $2.50 \pm 17.6$ & & $4.50 \pm 15.9$ & & $2.17 \pm 11.8$ & \\
\hline \multicolumn{10}{|l|}{ VA } \\
\hline $\mathrm{HA}+$ trehalose & 14 & $0.02 \pm 0.04$ & $I^{*}$ & $0.03 \pm 0.04$ & $0.85^{*}$ & $0.01 \pm 0.05$ & $0.16^{*}$ & $0.0 \pm 0.0$ & $0.28 *$ \\
\hline $\mathrm{HA}$ & 12 & $0.02 \pm 0.04$ & & $0.03 \pm 0.05$ & & $0.03 \pm 0.04$ & & $0.01 \pm 0.03$ & \\
\hline \multicolumn{10}{|c|}{ VA (difference with baseline) } \\
\hline $\mathrm{HA}+$ trehalose & 14 & $0.02 \pm 0.04$ & $\mathrm{I}^{* *}$ & $0.03 \pm 0.04$ & $0.85^{* *}$ & $0.01 \pm 0.05$ & $0.16 * *$ & $0.0 \pm 0.0$ & $0.28 * *$ \\
\hline $\mathrm{HA}$ & 12 & $0.02 \pm 0.04$ & & $0.03 \pm 0.05$ & & $0.03 \pm 0.04$ & & $0.01 \pm 0.03$ & \\
\hline van Bijsterveld scale & & & & & & & & & \\
\hline $\mathrm{HA}+$ trehalose & 14 & $2.43 \pm 2.0$ & $0.34^{\$}$ & $3.07 \pm 2.7$ & $0.81^{\$}$ & $1.79 \pm 1.9$ & $0.06^{\$}$ & $\mathrm{I} .29 \pm \mathrm{I} .3$ & $0.01^{\$}$ \\
\hline $\mathrm{HA}$ & 12 & $3.08 \pm 1.7$ & & $3.17 \pm 1.8$ & & $3.00 \pm 1.6$ & & $3.0 \pm 1.8$ & \\
\hline van Bijsterveld scale & e (diff & erence with br & seline) & & & & & & \\
\hline $\mathrm{HA}$ + trehalose & 14 & $1.46 \pm 1.5$ & $0.61^{\$}$ & $2.08 \pm 2.6$ & $0.8^{\S}$ & $1.00 \pm 1.7$ & $0.27^{\Phi}$ & $0.46 \pm 1.1$ & $0.12^{\$}$ \\
\hline $\mathrm{HA}$ & 12 & $1.83 \pm 1.7$ & & $1.92 \pm 1.7$ & & $1.75 \pm \mathrm{I} .4$ & & $1.75 \pm 2.0$ & \\
\hline Oxford scale & & & & & & & & & \\
\hline $\mathrm{HA}+$ trehalose & 14 & $0.86 \pm 0.8$ & $0.05^{\$}$ & $1.07 \pm 1$ & $0.16^{\$}$ & $0.75 \pm 0.7$ & $0.02^{\$}$ & $0.36 \pm 0.5$ & $0.00^{\$}$ \\
\hline $\mathrm{HA}$ & 12 & $1.42 \pm 0.5$ & & I.58 \pm 0.7 & & $1.42 \pm 0.5$ & & $1.50 \pm 0.7$ & \\
\hline Oxford scale (differ & rence & with baseline) & & & & & & & \\
\hline $\mathrm{HA}+$ trehalose & 14 & $0.43 \pm 0.8$ & $0.09 \$$ & $0.64 \pm 1 . I$ & $0.27^{\$}$ & $0.42 \pm 0.7$ & $0.15^{\$}$ & $-0.07 \pm 0.6$ & $0.00^{\$}$ \\
\hline $\mathrm{HA}$ & 12 & $0.92 \pm 0.7$ & & $1.08 \pm 0.9$ & & $0.92 \pm 0.8$ & & $1.0 \pm 0.9$ & \\
\hline NEI/Industry Work & shop & scale & & & & & & & \\
\hline $\mathrm{HA}+$ trehalose & 14 & $1.21 \pm 1.3$ & $0.91^{\$}$ & $2.07 \pm 2.8$ & $I^{\$}$ & $0.07 \pm 0.3$ & $0.0^{\$}$ & $0.2 I \pm 0.4$ & $0.07^{\$}$ \\
\hline $\mathrm{HA}$ & 12 & $1.33 \pm 1.7$ & & $2.08 \pm 2.9$ & & $1.50 \pm \mathrm{I} .7$ & & $2.0 \pm 3.4$ & \\
\hline $\mathrm{NEI} /$ Industry scale & (differ & ence with bas & line) & & & & & & \\
\hline $\mathrm{HA}+$ trehalose & 14 & $1.14 \pm 1.3$ & $0.96^{\$}$ & $2.0 \pm 2.8$ & $I^{\$}$ & $0.00 \pm 0.4$ & $0.02^{\$}$ & $0.14 \pm 0.5$ & $0.12^{\$}$ \\
\hline $\mathrm{HA}$ & 12 & $1.25 \pm 1.8$ & & $2.0 \pm 2.9$ & & $1.42 \pm 1.8$ & & $1.92 \pm 3.4$ & \\
\hline TBUT & & & & & & & & & \\
\hline $\mathrm{HA}$ + trehalose & 14 & $6.29 \pm 5.3$ & $0.36^{*}$ & $6.18 \pm 6.3$ & $0.73^{*}$ & $9.0 \pm 7.6$ & $0.25^{*}$ & $6.86 \pm 5.7$ & $0.9 *$ \\
\hline $\mathrm{HA}$ & 12 & $4.79 \pm 1.8$ & & $6.92 \pm 4.0$ & & $6.21 \pm 3.2$ & & $6.58 \pm 4.8$ & \\
\hline TBUT (difference $\mathrm{n}$ & vith $b$ & aseline) & & & & & & & \\
\hline $\mathrm{HA}+$ trehalose & 14 & $-4.82 \pm 2.3$ & $0.74 * *$ & $-4.93 \pm 1.7$ & $0.44 * *$ & $-2.11 \pm 3.4$ & $0.99 * *$ & $-4.25 \pm 5.6$ & $0.53 * *$ \\
\hline $\mathrm{HA}$ & 12 & $-9.04 \pm 6.8$ & & $-6.92 \pm 4.7$ & & $-7.63 \pm 5.4$ & & $-7.25 \pm 7.0$ & \\
\hline
\end{tabular}

Notes: *Student's $t$-test; **ANOVA paired test; ${ }^{\$}$ Mann-Whitney U-test.

Abbreviations: HA, hyaluronic acid; NEI, National Eye Institute; OSDI, Ocular Surface Disease Index; SANDE, Symptom Assessment in Dry Eye; SD, standard deviation; TBUT, tear breakup time; VA, visual acuity; ANOVA, analysis of variance. 


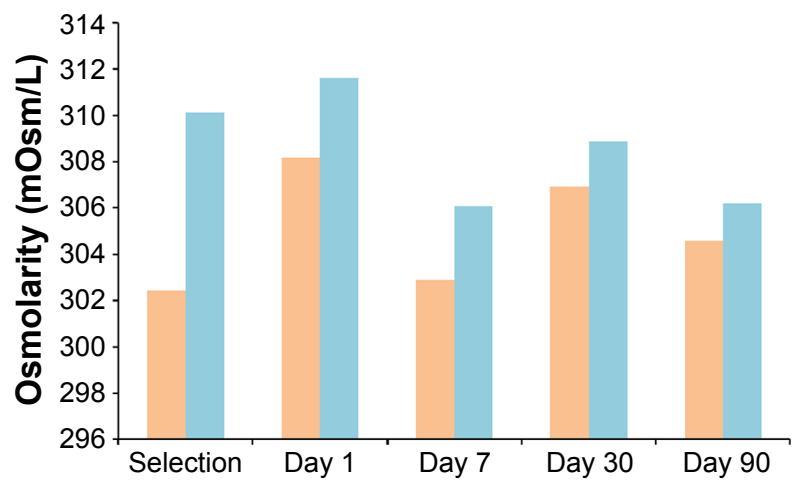

Figure I Mean tear osmolarity values measured in patients treated with Thealoz ${ }^{\circledR}$ (blue) and without Thealoz ${ }^{\circledR}$ (orange).

\section{Discussion}

Postoperative dry eye is still a challenge for the refractive surgeon. Its development affects the satisfaction of our patients, who often require immediate results and quick recovery. We have no accurate diagnostic test that can predict which patients will suffer clinically relevant dryness after refractive surgery. Dry eye disease symptoms may occur postoperatively even in individuals with a preoperative study within normal parameters. Some studies have suggested that the risk factors include the ablation depth and thickness of the flap, the degree of preoperative myopia, ${ }^{16}$ female sex, ${ }^{17}$ or the position of the hinge. ${ }^{18}$ Although the mechanisms involved in the development of dry eye are not fully understood, some etiopathogenic mechanisms that have been proposed are the alteration in the sensory input secondary to the flap transection and ablation, the reduction in the blinking reflex, drug toxicity, altered conjunctival goblet glands caused by microkeratome suction, or modification of the central corneal conformation. ${ }^{19}$

The strong decrease in the postoperative TBUT found in our study for both groups is consistent with the results published by other authors. ${ }^{20,21}$ This instability has been suggested as responsible for the reduction in VA associated with increased higher-order aberrations even when the sphero-cylindrical correction has been successful. ${ }^{22}$ Despite this alteration of the tear film, the VA of our patients was not diminished in any of the groups and questionnaires for symptoms related to visual satisfaction were not rated negatively by any of the individuals studied, although the score could be confounded by the refractive correction of the subject and the satisfaction derived from it.

Table 3 Osmolarity and lissamine green staining measurements throughout the study

\begin{tabular}{|c|c|c|c|c|c|c|c|c|c|c|c|}
\hline \multirow[t]{3}{*}{ Patient } & \multirow[t]{3}{*}{ Eye } & \multicolumn{10}{|l|}{ Visit } \\
\hline & & \multicolumn{2}{|c|}{ Preoperative } & \multicolumn{2}{|l|}{ Day I } & \multicolumn{2}{|l|}{ Day 7} & \multicolumn{2}{|c|}{ Day 30} & \multicolumn{2}{|c|}{ Day 90} \\
\hline & & OSM & LG & OSM & LG & OSM & LG & OSM & LG & OSM & LG \\
\hline \multirow[t]{2}{*}{ I } & Right & 295 & 0 & 300 & 1 & 288 & 0 & 296 & 0 & 302 & 0 \\
\hline & Left & 303 & 0 & 305 & I & 301 & 1 & 288 & 1 & 297 & 1 \\
\hline \multirow[t]{2}{*}{2} & Right & 299 & 0 & 294 & I & 292 & 1 & 291 & 1 & 305 & 2 \\
\hline & Left & 311 & I & 310 & 2 & 296 & I & 290 & I & 300 & 1 \\
\hline \multirow[t]{2}{*}{3} & Right & 304 & 0 & 311 & I & 324 & 1 & 313 & I & 300 & I \\
\hline & Left & 306 & 0 & 308 & I & 291 & 1 & 316 & I & 294 & I \\
\hline \multirow[t]{2}{*}{4} & Right & 302 & 0 & 302 & 0 & 289 & 0 & 282 & 0 & 296 & 0 \\
\hline & Left & 288 & I & 294 & I & 300 & 0 & 286 & 1 & 294 & I \\
\hline \multirow[t]{2}{*}{5} & Right & 308 & I & 311 & 2 & 301 & I & 319 & I & 300 & I \\
\hline & Left & 317 & I & 323 & 2 & 296 & 2 & 321 & 2 & 323 & 2 \\
\hline \multirow[t]{2}{*}{6} & Right & 311 & I & 316 & I & 300 & 2 & 335 & 2 & 295 & 2 \\
\hline & Left & 342 & I & 310 & 2 & 317 & 2 & 325 & 2 & 314 & 1 \\
\hline \multirow[t]{2}{*}{7} & Right & 277 & I & 306 & 2 & 305 & 2 & 305 & I & 298 & 1 \\
\hline & Left & 281 & I & 321 & I & 310 & 2 & 304 & 2 & 300 & 1 \\
\hline \multirow[t]{2}{*}{8} & Right & 306 & 0 & 316 & I & 303 & I & 304 & I & 313 & I \\
\hline & Left & 295 & I & 302 & I & 302 & 1 & 316 & 1 & 308 & 1 \\
\hline \multirow[t]{2}{*}{9} & Right & 316 & I & 301 & I & 298 & 1 & 303 & 1 & 326 & 0 \\
\hline & Left & 297 & 0 & 300 & 0 & 330 & I & 319 & I & 298 & 0 \\
\hline \multirow[t]{2}{*}{10} & Right & 307 & I & 326 & 0 & 308 & 1 & 317 & 0 & 306 & 0 \\
\hline & Left & 322 & I & 315 & I & 304 & 1 & 326 & 0 & 307 & 0 \\
\hline \multirow[t]{2}{*}{11} & Right & 300 & 0 & 294 & I & 297 & 2 & 300 & 2 & 301 & 2 \\
\hline & Left & 325 & I & 302 & 2 & 309 & 1 & 304 & 2 & 313 & 2 \\
\hline \multirow[t]{2}{*}{12} & Right & 334 & 0 & 365 & 2 & 306 & 3 & 300 & I & 315 & I \\
\hline & Left & 314 & 0 & 312 & I & 308 & 3 & 328 & I & 311 & 1 \\
\hline \multirow[t]{2}{*}{13} & Right & 304 & 0 & 301 & I & 316 & 2 & 310 & 1 & 315 & 0 \\
\hline & Left & 307 & 0 & 316 & I & 317 & 2 & 312 & 2 & 311 & 1 \\
\hline
\end{tabular}

Abbreviations: OSM, osmolarity; LG, lissamine green staining. 
The absence of differences observed between the two groups for tear osmolarity is an expected result because the surgical aggression was the same for all patients. The lowest levels of osmolarity in the ocular surface of the patients were the same for both groups and coincided with the time of the highest frequency of instillation of Hyabak, a hypotonic solution $(202 \pm 2 \mathrm{mOsm} / \mathrm{L})$. It should be noted that all patients were instructed not to apply the lubricant in the 120 minutes prior to any of the visits in order to better quantify the changes generated in the ocular surface. The decrease in aqueous secretion with a resulting decrease of TBUT, also with no differences between the groups, may be responsible for the larger concentration of tear film solutes in the patients. Despite the absence of differences for these variables, we did observe that patients with higher preoperative osmolarity were those showing a stronger alteration in staining. Of these, those who were in the group with trehalose were the ones that most benefited from this treatment (Table 3).

The most relevant results of this study are those concerning the vital stains. As can be seen in Table 2, we found larger differences in the variables that evaluate cell vitality between the two groups. Thus, the interaction of trehalose with membrane lipids could provide extra protection against surgical trauma and increased osmolarity, resulting in lower rates of inflammation and cell death. ${ }^{23}$

Previous studies have highlighted the benefits of treatment with trehalose in vitro, ${ }^{24,25}$ ex vivo, ${ }^{26}$ or in live-animal models, ${ }^{27}$ and in subjects with dry eye. ${ }^{28-30}$ However, this is the first study that evaluates the usefulness of trehalose after LASIK.

The results of objective variables were supported by the subjective tests that the subjects completed during the study. The improvement in the staining tests thus correlated with greater sense of comfort in our patients, and lower perception of symptoms and severity, in the SANDE test. In the OSDI test, despite no statistical differences between groups, the scores reached baseline levels in the exploration of day 7 , and were even better in subsequent visits. However, in the group treated only with HA, we observed a trend of slower recovery.

The major limitation of the study is the small number of patients. Several variables analyzed, such as those of the van Bijsterveld or Oxford scales on day 30, showed values barely significant. We are aware that a higher number of patients would have improved the statistical power and therefore the chances of finding differences between the two groups. In addition, the gender unbalance in our study could be another important limitation to the interpretation of the data because female patients could be at higher risk for dry eye syndrome. ${ }^{17}$ Finally, we compared results between the patients and not between eyes of the same patient to avoid potential confusions in the treatment. We considered that indicating a different postsurgical treatment for each eye in the same individual would add stress to the patient.

\section{Conclusion}

In conclusion, we observed time-dependent clinical changes in both intervention groups, which resulted in the appearance of a transient postoperative dry eye after LASIK. However, the differences found for some variables indicate that the recovery of the tear and cell homeostasis was best for the group treated with $3 \%$ trehalose as an adjuvant, concluding, therefore, the possible superiority of such treatment after LASIK compared to treatment with HA solution exclusively. Further investigation on a larger group of patients will be necessary to determine if adjuvant treatment with trehalose is a good choice for patients undergoing refractive surgery.

\section{Disclosure}

Thea laboratories provided financial support for the statistical analysis of the study and translation of this article. The authors report no other conflicts of interest or commercial interest in this work.

\section{References}

1. Levinson BA, Rapuano CJ, Cohen EJ, Hammersmith KM, Ayres BD, Laibson PR. Referrals to the Wills Eye Institute Cornea Service after laser in situ keratomileusis: reasons for patient dissatisfaction. J Cataract Refract Surg. 2008;34(1):32-39.

2. Jabbur NS, Sakatani K, O'Brien TP. Survey of complications and recommendations for management in dissatisfied patients seeking a consultation after refractive surgery. J Cataract Refract Surg. 2004; 30(9):1867-1874.

3. Chao C, Stapleton F, Zhou X, Chen S, Zhou S, Golebiowski B. Structural and functional changes in corneal innervation after laser in situ keratomileusis and their relationship with dry eye. Graefes Arch Clin Exp Ophthalmol. 2015;253(11):2029-2039.

4. Bower KS, Sia RK, Ryan DS, Mines MJ, Dartt DA. Chronic dry eye in photorefractive keratectomy and laser in situ keratomileusis: manifestations, incidence, and predictive factors. J Cataract Refract Surg. 2015;41(12):2624-2634.

5. Situ P, Simpson TL, Fonn D, Jones LW. Conjunctival and corneal pneumatic sensitivity is associated with signs and symptoms of ocular dryness. Invest Ophthalmol Vis Sci. 2008;49(7):2971-2976.

6. Quinto GG, Camacho W, Behrens A. Postrefractive surgery dry eye. Curr Opin Ophthalmol. 2008;19(4):335-341.

7. The definition and classification of dry eye disease: report of the definition and classification subcommittee of the international dry eye workshop. Ocul Surf. 2007;5(2):75-92.

8. Management and therapy of dry eye disease: report of the management and therapy subcommittee of the international dry eye workshop. Ocul Surf. 2007;5(2):163-178.

9. Leslie SB, Israeli E, Lighthart B, Crowe JH, Crowe LM. Trehalose and sucrose protect both membranes and proteins in intact bacteria during drying. Appl Environ Microbiol. 1995;61(10):3592-3597. 
10. Luyckx J, Baudouin C. Trehalose: an intriguing disaccharide with potential for medical application in ophthalmology. Clin Ophthalmol. 2011;5:577-581.

11. Schiffman RM, Christianson MD, Jacobsen G, Hirsch JD, Reis BL. Reliability and validity of the ocular surface disease index. Arch Ophthalmol. 2000;118(5):615-621.

12. Schaumberg DA, Gulati A, Mathers WD, et al. Development and validation of a short global dry eye symptom index. Ocul Surf. 2007; 5(1):50-57.

13. Van Bijsterveld OP. Diagnostic tests in the Sicca syndrome. Arch Ophthalmol. 1969;82(1):10-14.

14. Bron AJ, Evans VE, Smith JA. Grading of corneal and conjunctival staining in the context of other dry eye tests. Cornea. 2003;22(7): 640-650.

15. Lemp MA. Report of the National Eye Institute/Industry workshop on clinical trials in dry eyes. CLAO J. 1995;21(4):221-232.

16. De Paiva CS, Chen Z, Koch DD, et al. The incidence and risk factors for developing dry eye after myopic LASIK. Am J Ophthalmol. 2006;141(3):438-445.

17. Shoja MR, Besharati MR. Dry eye after LASIK for myopia: incidence and risk factors. Eur J Ophthalmol. 2007;17(1):1-6.

18. Feng YF, Yu JG, Wang DD, et al. The effect of hinge location on corneal sensation and dry eye after LASIK: a systematic review and metaanalysis. Graefes Arch Clin Exp Ophthalmol. 2013;251(1):357-366.

19. Toda I. LASIK and the ocular surface. Cornea. 2008;27(Suppl 1): S70-S76.

20. Konomi K, Chen LL, Tarko RS, et al. Preoperative characteristics and a potential mechanism of chronic dry eye after LASIK. Invest Ophthalmol Vis Sci. 2008;49(1):168-174.

21. Yu EYW, Leung A, Rao S, Lam DSC. Effect of laser in situ keratomileusis in tear stability. Ophthalmology. 2000;107(12):2131-2135.
22. Campbell C. The effect of tear film on higher order corrections applied to the corneal surface during wavefront-guided refractive surgery. $J$ Refract Surg. 2005;21(5):S519-S524.

23. Baudouin C, Aragona P, Messmer EM, et al. Role of hyperosmolarity in the pathogenesis and management of dry eye disease: proceedings of the OCEAN group meeting. Ocul Surf. 2013;11(4):246-258.

24. Hill-Bator A, Misiuk-Hojło M, Marycz K, Grzesiak J. Trehalose-based eye drops preserve viability and functionality of cultured human corneal epithelial cells during desiccation. Biomed Res Int. 2014;2014 292139.

25. Chen W, Zhang X, Liu M, et al. Trehalose protects against ocular surface disorders in experimental murine dry eye through suppression of apoptosis. Exp Eye Res. 2009;89(3):311-318.

26. Hovakimyan M, Ramoth T, Löbler M, et al. Evaluation of protective effects of trehalose on desiccation of epithelial cells in three dimensional reconstructed human corneal epithelium. Curr Eye Res. 2012; 37(11):982-989.

27. Li J, Roubeix C, Wang Y, et al. Therapeutic efficacy of trehalose eye drops for treatment of murine dry eye induced by an intelligently controlled environmental system. Mol Vis. 2012;18:317-329.

28. Pinto-Bonilla JC, Del Olmo-Jimeno A, Llovet-Osuna F, HernándezGalilea E. A randomized crossover study comparing trehalose/ hyaluronate eyedrops and standard treatment: patient satisfaction in the treatment of dry eye syndrome. Ther Clin Risk Manag. 2015;11: 595-603.

29. Matsuo T, Tsuchida Y, Morimoto N. Trehalose eye drops in the treatment of dry eye syndrome. Ophthalmology. 2002;109(11):2024-2029.

30. Schmidl D, Schmetterer L, Witkowska KJ, et al. Tear film thickness after treatment with artificial tears in patients with moderate dry eye disease. Cornea. 2015;34(4):421-426.
Clinical Ophthalmology

\section{Publish your work in this journal}

Clinical Ophthalmology is an international, peer-reviewed journa covering all subspecialties within ophthalmology. Key topics include: Optometry; Visual science; Pharmacology and drug therapy in eye diseases; Basic Sciences; Primary and Secondary eye care; Patien Safety and Quality of Care Improvements. This journal is indexed on

\section{Dovepress}

PubMed Central and CAS, and is the official journal of The Society of Clinical Ophthalmology (SCO). The manuscript management system is completely online and includes a very quick and fair peer-review system, which is all easy to use. Visit http://www.dovepress.com/ testimonials.php to read real quotes from published authors. 